\title{
Mortality in tongue cancer patients treated by curative surgery: A retrospective cohort study from CGRD
}

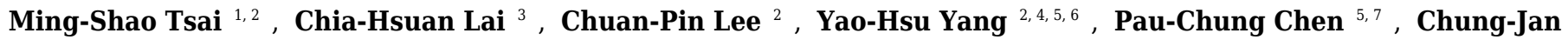 \\ Kang ${ }^{8}$, Geng-He Chang ${ }^{1}$, Yao-Te Tsai ${ }^{1}$, Chang-Hsien Lu ${ }^{9}$, Chih-Yen Chien ${ }^{10}$, Chi-Kuang Young ${ }^{11}$, Ku-Hao \\ Fang ${ }^{8}$, Chin-Jui Liu ${ }^{1}$, Re-Ming A Yeh ${ }^{1}$, Wen-Cheng Chen ${ }^{\text {Corresp. } 2,3,12}$ \\ 1 \\ 1 Department of Otolaryngology - Head and Neck Surgery, Chiayi Chang Gung Memorial Hospital, Chiayi, Taiwan \\ 2 Center of Excellence for Chang Gung Research Datalink, Chiayi Chang Gung Memorial Hospital, Chiayi, Taiwan \\ 3 Department of Radiation Oncology, Chiayi Chang Gung Memorial Hospital, Chiayi, Taiwan \\ 4 Department of Traditional Chinese Medicine, Chiayi Chang Gung Memorial Hospital, Chiayi, Taiwan \\ 5 Institute of Occupational Medicine and Industrial Hygiene, National Taiwan University College of Public Health, Taipei, Taiwan \\ 6 School of Traditional Chinese Medicine, College of Medicine, Chang Gung University, Taoyuan, Taiwan \\ 7 Department of Environmental and Occupational Medicine, National Taiwan University Hospital, Taipei, Taiwan \\ 8 Department of Otolaryngology - Head and Neck Surgery, Linkou Chang Gung Memorial Hospital, Taoyuan, Taiwan \\ 9 Department of Medical Oncology, Chiayi Chang Gung Memorial Hospital, Chiayi, Taiwan \\ 10 Department of Otolaryngology, Kaohsiung Chang Gung Memorial Hospital, Kaohsiung, Taiwan \\ 11 Department of Otolaryngology - Head and Neck Surgery, Keelung Chang Gung Memorial Hospital, Keelung, Taiwan \\ 12 College of Medicine, Chang Gung University, Taoyuan, Taiwan
}

Corresponding Author: Wen-Cheng Chen

Email address: danielchen@cgmh.org.tw

Background: Our study aimed to compare the outcomes of surgical treatment of the tongue cancer patients in three different age groups.

Methods: From 2004 to 2013, we retrospectively analyzed the clinical data of 1712 patients who were treated in the four institutions constituting the Chang Gung Memorial Hospitals (CGMH). We divided and studied the patients in three age groups: Group 1, younger ( $<65$ years); Group 2, young old (65 to $<75$ ); and Group 3, older old patients ( $\geq 75$ years).

Results: Multivariate analyses determined the unfavorable, independent prognostic factors of overall survival to be male sex, older age, advanced stage, advanced T, N classifications, and surgery plus chemotherapy. No significant differences were found in adjusted hazard ratios (HR) of death in earlystage disease (stage I-II) among Group 1 (HR 1.0), Group 2 [HR 1.43, 95\% confidence interval (Cl) $0.87-2.34, p=0.158$ ], and Group 3 (HR 1.22, 95\% Cl 0.49-3.03, $p=0.664$ ) patients. However, amongst advanced-stage patients (stage III-IV), Group 3 (HR 2.53, 95\% Cl 1.46-4.38, $p=0.001$ ) showed significantly worse survival than the other two groups after other variables were adjusted for. Fourteen out of 21 older old, advanced-staged patients finally died, and most of the mortalities were noncancerogenic (9/14,64.3\%), and mostly occurred within 1 year (12/14, 85\%) after cancer diagnosis. These non-cancer cause of death included underlying diseases in combination with infection, pneumonia, poor nutrition status, and trauma.

Conclusions: Our study showed that advanced T classification (T3-4), positive nodal metastasis (N1-3) and poorly differentiated tumor predicted poor survival for all patients. Outcome of early-stage patients (stage I-II) among three age groups were not significantly different. However, for advanced-stage patients (stage III-IV), the older old patients $(\geq 75)$ had significantly worse survival than the other two 
patient groups. Therefore, for early-stage patients, age should not deny them to receive optimal treatments. However, older old patients $(\geq 75)$ with advanced cancer should be comprehensively assessed by geriatric tools before surgical treatment and combined with intensive postoperative care to improve outcome, especially the unfavorable non-cancerogenic mortalities within 1 year after cancer diagnosis. 
4 Ming-Shao Tsai, $\mathrm{MD}^{1,2}$, Chia-Hsuan Lai, $\mathrm{MD}^{3}$, Chuan-Pin Lee, PhD², Yao-Hsu Yang, MD,

$5 \mathrm{MPH}^{2,4,5,6}$, Pau-Chung Chen, MD, PhD ${ }^{5,7}$, Chung-Jan Kang, MD ${ }^{8}$, Geng-He Chang, MD ${ }^{1}$, Yao-

6 Te Tsai, MD ${ }^{1}$, Chang-Hsien Lu MD ${ }^{9}$, Chih-Yen Chien, MD ${ }^{10}$, Chi-Kuang Young, MD ${ }^{11}$, Ku-

7 Hao Fang, $\mathrm{MD}^{8}$, Chin-Jui Liu MD ${ }^{1}$, Re-Ming Yeh, $\mathrm{MD}^{1}$ and Wen-Cheng Chen $\mathrm{MD}^{2,3,12}$

8

$9 \quad{ }^{1}$ Department of Otolaryngology - Head and Neck Surgery, Chiayi Chang Gung Memorial

10 Hospital, Chiayi, Taiwan

$11{ }^{2}$ Center of Excellence for Chang Gung Research Datalink, Chiayi Chang Gung Memorial

12 Hospital, Chiayi, Taiwan

$13{ }^{3}$ Department of Radiation Oncology, Chiayi Chang Gung Memorial Hospital, Chiayi, Taiwan

$14{ }^{4}$ Department of Traditional Chinese Medicine, Chiayi Chang Gung Memorial Hospital, Chiayi,

15 Taiwan

16 Institute of Occupational Medicine and Industrial Hygiene, National Taiwan University College

17 of Public Health, Taipei, Taiwan

$18{ }^{6}$ School of Traditional Chinese Medicine, College of Medicine, Chang Gung University, 
19 Taoyuan, Taiwan

$20{ }^{7}$ Department of Environmental and Occupational Medicine, National Taiwan University Hospital

21 and National Taiwan University College of Medicine, Taipei, Taiwan

$22{ }^{8}$ Department of Otorhinolaryngology - Head and Neck Surgery, Linkou Chang Gung Memorial

23 Hospital, Taoyuan, Taiwan

$24{ }^{9}$ Department of Medical Oncology, Chiayi Chang Gung Memorial Hospital, Chiayi, Taiwan

$25{ }^{10}$ Department of Otolaryngology - Head and Neck Surgery, Kaohsiung Chang Gung Memorial

26 Hospital, Kaohsiung, Taiwan

$27{ }^{11}$ Department of Otolaryngology - Head and Neck Surgery, Keelung Chang Gung Memorial

28 Hospital, Keelung, Taiwan

$29{ }^{12}$ College of Medicine, Chang Gung University, Taoyuan, Taiwan

\section{Corresponding author: Wen-Cheng Chen, MD}

32 Department of Radiation Oncology, Chang Gung Memorial Hospital, Chiayi. No.6, Sec. W.,

33 Jiapu Rd., Puzi City, Chiayi County 613, Taiwan (R.O.C.)

34 E-mail: danielchen@cgmh.org.tw

35 TEL.: 886-5-362-1000 ext. 2010; FAX: 886-5-362-3002 


\section{ABSTRACT}

37 Background: Our study aimed to compare the survival rate of the tongue cancer patients

38 receiving curative surgery in three different age groups.

39 Methods: From 2004 to 2013, we retrospectively analyzed the clinical data of 1712 patients who

40 were treated in the four institutions constituting the Chang Gung Memorial Hospitals (CGMH).

41 We divided and studied the patients in three age groups: Group 1, younger ( $<65$ years); Group 2,

42 young old ( 65 to $<75)$; and Group 3, older old patients $(\geq 75$ years).

43 Results: Multivariate analyses determined the unfavorable, independent prognostic factors of

44 overall survival to be male sex, older age, advanced stage, advanced $\mathrm{T}, \mathrm{N}$ classifications, and

45 surgery plus chemotherapy. No significant differences were found in adjusted hazard ratios (HR)

46 of death in early-stage disease (stage I-II) among Group 1 (HR 1.0), Group 2 [HR 1.43, 95\%

47 confidence interval (CI) $0.87-2.34, p=0.158$ ], and Group 3 (HR 1.22, 95\% CI 0.49-3.03, $p=$

48 0.664) patients. However, amongst advanced-stage patients (stage III-IV), Group 3 (HR 2.53,

$4995 \%$ CI $1.46-4.38, p=0.001)$ showed significantly worse survival than the other two groups

50 after adjusting for other variables. Fourteen out of 21 older old, advanced-staged patients finally

51 died, and most of the mortalities were non-cancerogenic $(9 / 14,64.3 \%)$, and mostly occurred

52 within 1 year $(12 / 14,85 \%)$ after cancer diagnosis. These non-cancer cause of death included

53 underlying diseases in combination with infection, pneumonia, poor nutrition status, and fall- 
54 related injury.

55 Conclusions: Our study showed that advanced T classification (T3-4), positive nodal metastasis

56 (N1-3) and poorly differentiated tumor predicted poor survival for all patients. The overall

57 survival of early-stage patients (stage I-II) among three age groups were not significantly

58 different. However, for advanced-stage patients (stage III-IV), the older old patients ( $\geq 75)$ had

59 significantly worse survival than the other two patient groups. Based on the present study, we

60 suggest that age should not deny early stage patients to receive optimal oncological treatments.

61 However, older old patients $(\geq 75)$ with advanced cancer should be comprehensively assessed by

62 geriatric tools before surgical treatment and combining with intensive postoperative care to

63 improve survival.

64

65 


\section{Introduction}

67 Tongue is the most common site of intraoral cancers in Taiwan and most other countries

68 (Huang et al., 2008; MHW, 2016; Moore et al., 2000). The tongue cancer patients are

69 predominantly male, and incidence of tongue cancer, peaks at 45-65 years in male and 55-75

70 years of age in female (MHW, 2016). According to a recent national cancer registry's annual

71 report of Taiwan, incidence and mortality of head and neck cancers (ICD-O-3, C00-C14) rank

72 sixth and fifth, respectively (MHW, 2016).

73 Taiwan, like the other developed countries, has gradually transformed into a society of the

74 aged with those older than 65 years accounting for $12 \%$ of its population (Kowal et al., 2012;

75 NDC, 2014). This figure is likely to hit $20 \%$ in 2025, turning Taiwan into a super-ageing society

76 (NDC, 2014). The numbers of elderly patients with tongue cancer is expected to increase in the

77 future. Nowadays, surgery is the therapeutic mainstay for early-stage tongue cancer, but it is

78 often part of a multi-modal approach to treat advanced disease (Calabrese et al., 2011). However,

79 many elderly patients may not be considered as candidates for aggressive multimodal treatments

80 due to other ageing-associated comorbidities, general debility, and concerns regarding low

81 tolerance to treatment and resulting toxicity (Siddiqui \& Gwede, 2012; Zabrodsky et al., 2004).

82 Recent reports on the relationship between elderly patients with head and neck cancer and

83 their prognosis have been conflicting (Airoldi et al., 2004; Bhattacharyya, 2003; Chang et al., 
84 2013; Clayman et al., 1998; Italiano et al., 2008; Kruse et al., 2010; Luciani et al., 2010;

85 Lusinchi et al., 1990; Ortholan et al., 2009; Sarini et al., 2001; Zabrodsky et al., 2004). Some

86 concluded that older patients suffered a worse survival than younger patients (Bhattacharyya,

87 2003; Chang et al., 2013; Clayman et al., 1998). However, many others failed to show a

88 significant difference between outcomes of old and young patients (Airoldi et al., 2004; Argiris

89 et al., 2004; Lusinchi et al., 1990; Sarini et al., 2001). In many previously published reports

90 (Airoldi et al., 2004; Bhattacharyya, 2003; Chang et al., 2013; Clayman et al., 1998; Italiano et

91 al., 2008; Kruse et al., 2010; Lusinchi et al., 1990; Ortholan et al., 2009; Sarini et al., 2001;

92 Zabrodsky et al., 2004), the cutoff age values $(65,70,75,80$, or 85 years) and the definition of

93 elderly patients were inconsistent. Besides, some previous reports included a small sample size

94 or lacked cancer staging. In the present study, we intend to focus on the survival outcomes of

95 older adults with homogenous tongue cancer receiving curative surgery in order to provide

96 evidence for preoperative risk explanations and decision making for the surgeons or oncologists.

97 The National Institute of Aging have classified the elderly patients into three age groups: 65-74

98 years as "young old", 75-84 years as "older old", and >85 years as "oldest old" (NIH, 1998).

99 Here, we compared treatment results of tongue cancer patients, stratifying by three age groups:

100 Group 1, $<65$ years (younger population); Group 2, 65-<75 years (young old population) and

101 Group 3, $\geq 75$ years (older old population). 


\section{Materials and methods}

104 Data Source

105 The data were obtained from the largest private hospital system in Taiwan, the Chang Gung

106 Memorial Hospital (CGMH), using the Chang Gung Research Database (CGRD). The database

107 combines original medical record from four medical institutes, Keelung CGMH, Linkou CGMH,

108 Chiayi CGMH, and Kaohsiung CGMH. They are located in the northeast, northern, central, and

109 southern regions of Taiwan, respectively. According to the Taiwanese national cancer registry's

110 report, this combined hospital system had treated $\sim 20 \%$ of head and neck cancer patients.

111 We retrospectively reviewed the CGRD database from January 2004 to December 2013, and

112 retrieved data of tongue cancer patients $(n=2487)$. We excluded patients with recurrent or

113 secondary oral cancers, or those with other malignancies $(n=471)$. Patients with poor

114 performance status $(\mathrm{ECOG} \geq 3$ ), end-stage renal disease, Child-Pugh $\mathrm{C}$ liver cirrhosis, or poor

115 heart or lung function, or who were unfit for surgery, were also excluded to reduce confounding

116 factors and bias. Finally, 1712 patients with primary tongue cancer who received curative

117 surgery were studied. The ethics review board of our institution approved the study (CGMH-IRB

118 No. 104-4642B).

120 Surgery, adjuvant therapy, and follow-up 
121 Patients were evaluated preoperatively according to the CGMH oral cavity cancer guidelines,

122 which were modified from the NCCN guideline (Pfister et al., 2000; Pfister et al., 2013).

123 Evaluations included patient history taking, physical examination, nasopharyngoscopy, complete

124 blood count, blood biochemistry, chest X-ray, electrocardiography, abdominal sonography and

125 panendoscopy, computed tomography or MRI of head and neck, and bone scan or FDG-PET.

126 Cancer staging accorded with the American Joint Committee on Cancer staging classification

127 (AJCC, 6th edition) (Edge \& Compton, 2010).

128 All patients were treated based on the CGMH oral cavity cancer guidelines. Tumors were

129 resected with at least $1 \mathrm{~cm}$ gross, safe margin in all patients. Level I-III cervical lymph node

130 resections were performed in patients without lymph node metastases. Level I-V cervical lymph

131 node resections or more extensive resections were done in patients with lymph node metastases.

132 All patients who received free-flap reconstruction were admitted to the ICU after surgery, and

133 were followed by intensive flap monitoring. Post-operative concurrent chemo-radiotherapy

134 (CCRT) with 60-70 Gray (1.8-2.0 Gray per fraction) and Cisplatin-based regimen (weekly 30 40

$135 \mathrm{mg} / \mathrm{m} 2 / \mathrm{wk} \times 6 \sim 7$ weeks) was administered in patients with positive surgical margins or

136 extracapsular extension of lymph nodes. In patients with other risk factors (such as T3/T4, N1,

$137 \mathrm{~N} 2 / \mathrm{N} 3$, perineural invasion, or vascular tumor embolism), postoperative radiotherapy (RT) with

138 60-70 Gray (1.8-2.0 Gray per fraction) was administered. However, in older patients or patients 
139 with multiple comorbidities, RT or chemotherapy (CT) programs were cancelled following

140 discussions with their families. We followed up the patients since their cancers' diagnosis until

141 death, cancer recurrence, or the last follow-up. All patients received regular postoperative

142 follow-up.

143

144 Age definitions, outcomes, and covariates

145 The final dataset was divided into 3 groups: Group 1, younger population ( $<65$ years); Group

1462 , young old population ( 65 to $<75$ years); and Group 3, older old population ( $\geq 75$ years). Patient

147 characteristics included age, gender, cancer TNM staging, histological grade, treatment

148 modalities (surgery, surgery with adjuvant RT or CT). The main outcome was overall survival

149 rate.

150

151 Statistical analysis

152 Gender, cancer staging, histological grade, and treatment modalities were compared amongst

153 the three Groups by the Pearson's $\chi^{2}$ test. We estimated the survival rates during the entire

154 follow-up period by the Kaplan-Meier method and compared survival rates amongst the three

155 groups by the Log-rank test. The multivariate Cox proportional hazards analysis was performed

156 for gender, age group, cancer stage, histological grade and treatment modalities. Statistical 
157 analyses used the statistical software $\mathrm{R}$ (version 3.1.3). For all tests, significance was defined at $p$

$158<0.05$

159 


\section{Results}

161

Patient characteristics and treatments

162 Patients' characteristics are presented in Table 1. The mean/median ages for Group 1, Group 2,

163 and Group 3 were 48.7/49, 68.7/69, and 79.5/79 years, respectively. The proportion of female

164 patients increased with age and were significantly different in three groups $(\mathrm{p}<0.001)$. Cancer

165 staging, T-N classification, and tumor differentiation were not significantly different among the

166 three Groups. The ratio of patients receiving surgery alone without CT or RT increased with

167 age and were significantly different amongst the three groups $(p=0.004)$. To clarify the

168 difference in treatment patterns among the three groups, all patients were further divided into

169 early (stage I-II) and advanced stages (stage III-IV) for comparison (Table 2). For early-stage

170 patients, 86.7\%, 85\%, and 81\% received surgery alone in Group 1, Group 2, and Group 3,

171 respectively. The treatment patterns were not significantly different among the three Groups ( $p=$

172 0.558). However, in patients with advanced-stage disease, adjuvant treatment (which were

173 usually needed for control of the advanced stage) was given to fewer patients with increasing age.

174 The proportion of advanced stage patients receiving adjuvant treatment were significantly

175 different among the three groups $(\mathrm{p}<0.001)$.

176 Survival

177 The medial follow-up times of all and surviving patients are 2.88 and 3.66 years respectively. 
178 Figure 1A shows the early-stage patients' overall survival curves. Survival rates were not

179 significantly different amongst Group 1, Group 2, and Group 3 patients (Log-rank test, $p=$

180 0.355). The 5-year survival rates were 83.9\% in Group 1; 76.8\% in Group 2; and 82.7\% in Group

1813.

182 Figure 1B shows the advanced-stage patients' overall survival curves. Group 3 had the worst

183 prognosis (Log-rank test, $p=0.002$ ). The 5-year survival rate was 55.0\% in Group 1, 46.1\% in

184 Group 2, and 29.4\% in Group 3. Table 3 shows the multivariate analysis data used to compare

185 the hazard ratios (HR) of death between different genders, the three Groups, stages (I and II vs

186 III and IV), T classifications (T1-2 vs T3-4), N classifications (N0 vs N1-3), tumor

187 differentiation (well to moderately differentiated $v s$ poorly differentiated), and treatments

188 (Surgery $v s$ Surgery + RT vs Surgery + CT vs Surgery + CCRT). For all patients, HR for death

189 was 1.39 times greater for the male than for the female patients $(95 \% \mathrm{CI}, 1.00-1.93 ; p=0.048)$.

190 After adjusting for other factors, Group 2 (HR 1.38, 95\% CI 1.02-1.87, $p=0.037$ ) and Group 3

191 (HR 1.91, 95\% CI 1.2-3.06, $p=0.007$ ) had greater likelihood of death than Group 1. Advanced-

192 stage (stage III-IV) patients had the worse survival (HR 1.64, 95\% CI 1.07-2.50, $p=0.022$ ) than

193 patients with early-stage diseases (stage I-II). Adjusted HR for death were 1.42 times (95\% CI

$1941.10-1.84, p=0.008)$ and 2.41 times $(95 \%$ CI 1.7-3.42, $p<0.001)$ for the advanced T (T3-4)

195 and N (N1-3) classifications than for the early T (T1-2) and N0. Poorly differentiated tumors 
196 also predicted poor survival rates than well differentiated and moderately differentiated tumors

197 (HR 1.51, 95\% CI 1.16-1.97, $p=0.003$ ). Surgery plus CT alone led to worse survival rates than

198 surgery alone (HR 1.97, 95\% CI 1.33-2.90, $p=0.001)$. Table 4 shows HR of death for early-

199 stage (stage I and II) patients. The adjusted HR for death was 1.64 times greater for the male than

200 for the female patients $(95 \%$ CI $0.92-2.94, p=0.095)$. The adjusted HR for death was greater for

201 the Group 2 (HR 1.43, 95\% CI 0.87-2.34, $p=0.158$ ) and Group 3 (HR 1.22, 95\% CI 0.49-3.03,

$202 p=0.664)$ than for Group 1, but the differences were not statistically significant. Table 5 shows

203 the HR of death for advanced-stage (stage III and IV) patients. The adjusted HR for death was

2041.16 times greater for the male than for the female patients $(95 \%$ CI $0.78-1.72, p=0.454)$. The

205 adjusted HR for death was significantly greater for Group 3 (HR 2.53, 95\% CI 1.46-4.38, $p=$

206 0.001) than for Group 1, but the difference was not significant for Group 2 (HR 1.19, 95\% CI

$2070.81-1.75, p=0.372$ ) as compared with Group 1.

208

209 Causes of death in Group 3 patients with advanced disease

210 Fourteen of the 21 advanced-staged, Group 3 patients died. Causes of death are listed in Table

211 6. Nearly all mortalities (12 out of 14, 85.7\%) occurred within 1 year after cancer diagnosis. The

212 causes of death were classified into cancer recurrence (4 patients, 28.6\%), non-cancerogenic

213 cause of death (9 patients, 64.3\%), and unknown ( 1 patient, 7.1\%). The non-cancer cause of 
214 death are the primary causes of death in this age group, including underlying diseases in

215 combination with infection, pneumonia, poor nutrition status, and trauma. Sixteen patients

$216(16 / 21,76.2 \%)$ were indicated to receive adjuvant therapy; however, 11 patients $(11 / 16,68.8 \%)$

217 completed the therapy. The surviving patients all completed the planned oncological treatments

218 (either surgery alone, or surgery and adjuvant treatments).

219 


\section{Discussion}

221 Our study showed that advanced T classification (T3-4), positive nodal metastasis (N1-3) and

222 poorly differentiated tumor predicted poor survival for all patients, which were compatible with

223 previous studies (Aksu et al., 2006; Goto et al., 2005; Liao et al., 2008). The male patients

224 showed significantly poor survival than the female patients for all patients, but showed no

225 significant difference after dividing all patients into early and advanced stages. This may be due

226 to the relatively smaller sample size of female (1504 men vs 208 women) in our study cohort.

227 Previously published literature on the outcomes of the surgical treatment of the tongue cancer in

228 different age groups has been controversial. Sarini et al. (Sarini et al., 2001) reported the

229 treatment outcomes of older patients ( $\geq 75$ years) with head and neck squamous cell carcinoma

230 did not differ significantly from younger patients' outcomes. Davidson et al. reported a large

231 series $(n=749)$ of the tongue cancer patients enrolled in the Surveillance, Epidemiology, and

232 End Results (SEER) database concluded that an increasing age predicted the worse disease-

233 specific survival (Davidson et al., 2001). Chang et al. reported old patients ( $>65$ years) with oral

234 cavity cancer had lower survival rate than young patients ( $<45$ years) (Chang et al., 2013).

235 However, no details of cancer staging were reported in these study (Chang et al., 2013; Davidson

236 et al., 2001). Jones et al. (Jones et al., 1998) and Clayman et al. (Clayman et al., 1998) also

237 reported that older patients with head and neck cancer had worse survival that younger patients. 
238 Nonetheless, oral cavity cancer patients comprised less than $25 \%$ to $60 \%$ of their patients.

239 In our study, we included 1712 homogeneous tongue cancer patients (1476 younger, 178

240 young old and 58 older old patients) with clear pathological staging after radical surgery, and

241 compared their overall survival rate with younger patients all treated under the standard

242 guidelines. Our study clearly showed that elderly patients are likely to face the worst survival

243 rate amongst the tongue cancer patients after having been treated by radical surgery. After

244 adjusting for other variables, young old and older old patients were more likely to die than

245 younger patients. No significant difference in adjusted HR of death was found for early-stage

246 patients (stage I-II) amongst the younger, young old, or older old patients which implied that age

247 should not deny older people to receive optimal treatment. However, for advanced-stage disease

248 (stage III-IV), the older old patients showed significantly worse survival than the other two

249 groups after adjusting for other variables.

250 Italiano et al. reported on 316 head and neck squamous cell carcinoma patients aged $>80$ years

251 receiving radiotherapy $(\mathrm{N}=180 ; 57.0 \%)$, surgery $(\mathrm{N}=97 ; 30.7 \%)$ and no treatment $(\mathrm{N}=39 ; 12.3 \%)$

252 (Italiano et al., 2008). They reported that outcomes of patients with stage I/II was similar to that

253 of younger patients, but those with stage III/IV showed poor survival. These results are in

254 agreement with our results. In our series, younger, young old, and older old patients received

255 similar treatment modalities (Table 2, 81.0 - 86.7 \% patients underwent surgery alone without 
256 CT or RT) and had comparably optimal survival rate in early-stage tongue cancer. Our data

257 represented the first evidence that old age $\geq 75$ years should not be a reason to deny patients of

258 early-staged tongue cancer to receive curative surgery.

259 For advanced-stage patients, older old patients had worst prognosis as compared with the other

260 two age groups. Fourteen out of 21 older old, advanced-staged patients finally died and most of

261 the mortalities occurred within 1 year after cancer diagnosis $(12 / 14,85.7 \%)$. The causes of

262 deaths were mostly non-cancerogenic $(9 / 14,64.3 \%)$ including underlying diseases in

263 combination with infection, pneumonia, poor nutrition status, and fall-related injury.

264 Reid et al. concluded that comorbidities also predict survival in the older people with head and

265 neck cancer (Reid et al., 2001). Previous studies have also emphasized the importance of careful

266 assessment of comorbidities, physical status, and patients' psychological profiling before

267 operation (Grenman et al., 2010; Kruse et al., 2010). Many studies have indicated regular

268 physical activity is essential for the elderly cancer patients to aid in the process of recovery,

269 improve fitness and prevent falls. (Cho et al., 2015; Genden et al., 2005; Keogh et al., 2015; Lee

270 et al., 2016; Pinto \& Ciccolo, 2010; Rock et al., 2012). Besides, our results (Table 2) showed that

271 the proportion of the patients who received postoperative CCRT was significantly low in the

272 elderly patients. Adjuvant RT or CT after surgery was indicated for eighteen of 21 older old,

273 advanced-staged patients, and was received by 11 of those patients (61\%). The reason for not 
274 receiving adjuvant therapy were advanced age $(n=4)$, comorbidities $(n=2)$, and early death $(n=1)$.

275 Thus, suboptimal treatments might increase the risk of cancer recurrence and disease metastasis

276 in cases with advanced disease.

277 The following measures possibly could improve the survival rate of the elderly patients with

278 tongue cancer: (1) thoroughly evaluating patients pre-operationally and controlling the

279 underlying disease (2) using geriatric assessment tools to predict mortality and assist treatment

280 decision-making process (Extermann \& Hurria, 2007; Italiano et al., 2008); (3) screening the

281 cancer intensively to diagnose cancer as early as possible (Reid, 2013); (4) ensuring that patients

282 receive post-operational rehabilitation for cancer-related deconditioning as soon as possible

283 (Saotome et al., 2015); (5) increasing nutrition supplementation and preventing choking and

284 aspiration pneumonia (Farhangfar et al., 2014); and (6) Modification of environmental hazards

285 and performing physical activities to prevent falls which is common in older cancer patients

286 (Cho et al., 2015; Keogh et al., 2015; Lee et al., 2016; Rock et al., 2012; Sattar et al., 2016;

287 Ungar \& Rafanelli, 2015).

288 Future research by incorporating these factors or measures should be considered in order to

289 improve survivals in those patients.

290 


\section{Conclusion}

292 Our study showed that advanced T classification (T3-4), positive nodal metastasis (N1-3) and

293 poorly differentiated tumor predicted poor survival for all patients. For early-stage patients (stage

294 I-II), the overall survival rate among the younger age, young old, and older old patients were not 295 significantly different. However, for advanced-stage patients (stage III-IV), the older old patients 296 ( $\geq 75)$ had significantly worse survival than the other two patient groups. Based on the present 297 study, we suggest that age should not deny early stage patients to receive optimal oncological 298 treatment. However, older old patients $(\geq 75)$ with advanced cancer should be comprehensively 299 assessed by geriatric tools before surgical treatment and combining with intensive postoperative 300 care to improve survival.

301

302 


\section{Acknowledgements:}

304 The authors would like to thank Center of Excellence for Chang Gung Research Datalink

305 (CORPG6D0161-2, CORPG6D0251-2) for the comments and assistance in data analysis.

306 


\section{FIGURE LEGENDS:}

308 Figure 1. Overall survival curves of early-stage (1A) and advanced-stage (1B) patients. 
310

311

312

313

314

315

316

317

318

319

320

321

322

323

324

325

326

327

328

329

330

331

332

333

334

335

336

337

338

339

340

341

342

343

344

\section{Reference:}

Airoldi M, Cortesina G, Giordano C, Pedani F, Gabriele AM, Marchionatti S, and Bumma C. 2004. Postoperative adjuvant chemoradiotherapy in older patients with head and neck cancer. Archives of Otolaryngology-Head \& Neck Surgery 130:161-166. DOI 10.1001/archotol.130.2.161

Aksu G, Karadeniz A, Saynak M, Fayda M, Kadehci Z, and Kocaelli H. 2006. Treatment results and prognostic factors in oral tongue cancer: analysis of 80 patients. International Journal of Oral and Maxillofacial Surgery 35:506-513. DOI 10.1016/j.ijom.2006.01.006

Argiris A, Li Y, Murphy BA, Langer CJ, and Forastiere AA. 2004. Outcome of elderly patients with recurrent or metastatic head and neck cancer treated with cisplatin-based chemotherapy. Journal of Clinical Oncology 22:262-268.

\section{DOI 10.1200/JCO.2004.08.039}

Bhattacharyya N. 2003. A matched survival analysis for squamous cell carcinoma of the head and neck in the elderly. The Laryngoscope 113:368-372.

\section{DOI 10.1097/00005537-200302000-00030}

Calabrese L, Bruschini R, Giugliano G, Ostuni A, Maffini F, Massaro MA, Santoro L, Navach V, Preda L, Alterio D, Ansarin M, and Chiesa F. 2011. Compartmental tongue surgery: Long term oncologic results in the treatment of tongue cancer. Oral Oncology 47:174-179. DOI 10.1016/j.oraloncology.2010.12.006

Chang T-S, Chang C-M, Ho H-C, Su Y-C, Chen L-F, Chou P, and Lee C-C. 2013. Impact of young age on the prognosis for oral cancer: a population-based study in Taiwan. PLoS ONE 8:e75855. DOI 10.1371/journal.pone.0075855

Cho J, Smith ML, Ahn S, Kim K, Appiah B, and Ory MG. 2015. Effects of an evidence-based falls risk-reduction program on physical activity and falls efficacy among oldest-old adults. Evidence-Based Programming for Older Adults:245. DOI 10.3389/fpubh.2014.00182

Clayman GL, Eicher SA, Sicard MW, Razmpa E, and Goepfert H. 1998. Surgical outcomes in head and neck cancer patients 80 years of age and older. Head \& Neck 20:216-223. DOI 10.1002/(SICI)1097-0347(199805)20:3<216::AID-HED6>3.0.CO;2-3

Davidson BJ, Root WA, and Trock BJ. 2001. Age and survival from squamous cell carcinoma of the oral tongue. Head \& Neck 23:273-279.

DOI 10.1002/hed.1030

Edge SB, and Compton CC. 2010. The American Joint Committee on Cancer: the 7th edition of the AJCC cancer staging manual and the future of TNM. Annals of Surgical Oncology 17:1471-1474. DOI 10.1245/s10434-010-0985-4

Extermann M, and Hurria A. 2007. Comprehensive geriatric assessment for older patients with 
345

346

347

348

349

350

351

352

353

354

355

356

357

358

359

360

361

362

363

364

365

366

367

368

369

370

371

372

373

374

375

376

377

378

379

380

cancer. Journal of Clinical Oncology 25:1824-1831.

DOI 10.1200/JCO.2007.10.6559

Farhangfar A, Makarewicz M, Ghosh S, Jha N, Scrimger R, Gramlich L, and Baracos V. 2014.

Nutrition impact symptoms in a population cohort of head and neck cancer patients:

multivariate regression analysis of symptoms on oral intake, weight loss and survival. Oral Oncology 50:877-883.

DOI 10.1016/j.oraloncology.2014.06.009

Genden EM, Rinaldo A, Shaha AR, Clayman GL, Werner JA, Suarez C, and Ferlito A. 2005. Treatment considerations for head and neck cancer in the elderly. The Journal of Laryngology \& Otology 119:169-174. DOI 10.1258/0022215053561521

Goto M, Hasegawa Y, Terada A, Hyodo I, Hanai N, ljichi K, Yamada H, Fujimoto Y, and Ogawa T. 2005. Prognostic significance of late cervical metastasis and distant failure in patients with stage I and II oral tongue cancers. Oral Oncology 41:62-69. DOI 10.1016/j.oraloncology.2004.06.007

Grenman R, Chevalier D, Gregoire V, Myers E, and Rogers S. 2010. Treatment of head and neck cancer in the elderly: European Consensus (panel 6) at the EUFOS Congress in Vienna 2007. European Archives of Oto-Rhino-Laryngology 267:1619-1621. DOI 10.1007/s00405-010-1263-6

Huang SF, Kang CJ, Lin CY, Fan KH, Yen TC, Wang HM, Chen IH, Liao CT, Cheng AJ, and Chang JT. 2008. Neck treatment of patients with early stage oral tongue cancer: comparison between observation, supraomohyoid dissection, and extended dissection. Cancer 112:1066-1075. DOI 10.1002/cncr.23278

Italiano A, Ortholan C, Dassonville O, Poissonnet G, Thariat J, Benezery K, Vallicioni J, Peyrade F, Marcy PY, and Bensadoun RJ. 2008. Head and neck squamous cell carcinoma in patients aged $>$ or $=80$ years: patterns of care and survival. Cancer 113:3160-3168. DOI 10.1002/cncr.23931

Jones AS, Beasley N, Houghton D, and Husband DJ. 1998. The effects of age on survival and other parameters in squamous cell carcinoma of the oral cavity, pharynx and larynx. Clinical Otolaryngology and Allied Sciences 23:51-56. DOI 10.1046/j.1365-2273.1998.00086.x

Keogh JW, Olsen A, Climstein M, Sargeant S, and Jones L. 2015. Benefits and Barriers of Cancer Practitioners Discussing Physical Activity with their Cancer Patients. Journal of Cancer Education:1-5. DOI 10.1007/s13187-015-0893-1

Kowal P, Chatterji S, Naidoo N, Biritwum R, Fan W, Ridaura RL, Maximova T, Arokiasamy P, Phaswana-Mafuya N, and Williams S. 2012. Data resource profile: the World Health Organization Study on global AGEing and adult health (SAGE). International Journal of 
381

382

383

384

385

386

387

388

389

390

391

392

393

394

395

396

397

398

399

400

401

402

403

404

405

406

407

408

409

410

411

412

413

414

415

416

Epidemiology 41:1639-1649.

\section{DOI 10.1093/ije/dys210}

Kruse AL, Bredell M, Luebbers HT, and Gratz KW. 2010. Head and neck cancer in the elderly: a retrospective study over 10 years (1999 - 2008). Head and Neck Oncology 2:25. DOI 10.1186/1758-3284-2-25

Lee CE, Warden SJ, Szuck B, and Lau Y. 2016. A Preliminary Study on the Efficacy of a Community-Based Physical Activity Intervention on Physical Function-Related Risk Factors for Falls Among Breast Cancer Survivors. American Journal of Physical Medicine \& Rehabilitation 95:561-570. DOI 10.1097/PHM.0000000000000440

Liao CT, Chang JT, Wang HM, Ng SH, Hsueh C, Lee LY, Lin CH, Chen IH, Huang SF, Cheng AJ, and Yen TC. 2008. Analysis of risk factors of predictive local tumor control in oral cavity cancer. Annals of Surgical Oncology 15:915-922.

DOI 10.1245/s10434-007-9761-5

Luciani A, Ascione G, Bertuzzi C, Marussi D, Codecà C, Di Maria G, Caldiera SE, Floriani I, Zonato $S$, and Ferrari D. 2010. Detecting disabilities in older patients with cancer: comparison between comprehensive geriatric assessment and vulnerable elders survey-13. Journal of Clinical Oncology 28:2046-2050. DOI 10.1200/JCO.2009.25.9978

Lusinchi A, Bourhis J, Wibault P, Le Ridant A, and Eschwege F. 1990. Radiation therapy for head and neck cancers in the elderly. International Journal of Radiation Oncology* Biology* Physics 18:819-823.

\section{DOI 10.1016/0360-3016(90)90403-7}

MHW. 2016. Cancer registry annual report of Taiwan 2012. Ministry of Health and Welfare, Taiwan. http://www.hpa.gov.tw/BHPNet/Web/Stat/Statistics.aspx

Moore SR, Johnson NW, Pierce AM, and Wilson DF. 2000. The epidemiology of tongue cancer: a review of global incidence. Oral Diseases 6:75-84.

DOI 10.1111/j.1601-0825.2000.tb00105.x

NDC. 2014. Population projection of Taiwan 2014-2061. National Development Council, Taiwan. http://www.ndc.gov.tw/Content_List.aspx?n=84223C65B6F94D72

NIH. 1998. Aging and old age as risk factors for multiple primary tumors. National Institute of Health, US. http://grants.nih.gov/grants/guide/pa-files/PA-99-030.html

Ortholan C, Lusinchi A, Italiano A, Bensadoun RJ, Auperin A, Poissonnet G, Bozec A, Arriagada R, Temam S, Benezery K, Thariat J, Tao Y, Janot F, Mamelle G, Vallicioni J, Follana P, Peyrade F, Sudaka A, Bourhis J, and Dassonville O. 2009. Oral cavity squamous cell carcinoma in 260 patients aged 80years or more. Radiotherapy and Oncology 93:516523. DOI 10.1016/j.radonc.2009.07.015

Pfister D, Ang K, Brockstein B, Colevas A, Ellenhorn J, Goepfert H, Hicks Jr W, Hong W, Kies M, 
417

418

419

420

421

422

423

424

425

426

427

428

429

430

431

432

433

434

435

436

437

438

439

440

441

442

443

444

445

446

447

448

449

450

451

452

and Lydiatt W. 2000. NCCN practice guidelines for head and neck cancers. Oncology (Williston Park, NY) 14:163.

https://www.nccn.org/professionals/physician_gls/f_guidelines.asp\#site

Pfister DG, Ang K-K, Brizel DM, Burtness BA, Busse PM, Caudell JJ, Cmelak AJ, Colevas AD, Dunphy F, and Eisele DW. 2013. Head and neck cancers, version 2.2013. Journal of the National Comprehensive Cancer Network 11:917-923.

https://www.nccn.org/professionals/physician_gls/f_guidelines.asp\#site

Pinto BM, and Ciccolo JT. 2010. Physical activity motivation and cancer survivorship. Physical Activity and Cancer: Springer, 367-387.

DOI 10.1007/978-3-642-04231-7_16

Reid BC. 2013. Visual screening for oral cancer may reduce oral cancer mortality in high-risk adult populations through early diagnosis and treatment. Journal of Evidence Based Dental Practice 13:174-176. DOI 10.1016/j.jebdp.2013.10.013

Reid BC, Alberg AJ, Klassen AC, Samet JM, Rozier RG, Garcia I, and Winn DM. 2001. Comorbidity and survival of elderly head and neck carcinoma patients. Cancer 92:2109-2116. DOI 10.1002/1097-0142(20011015)92:8<2109::AID-CNCR1552>3.0.CO;2-M

Rock CL, Doyle C, Demark-Wahnefried W, Meyerhardt J, Courneya KS, Schwartz AL, Bandera EV, Hamilton KK, Grant B, and McCullough M. 2012. Nutrition and physical activity guidelines for cancer survivors. CA: A Cancer Journal for Clinicians 62:242-274. DOI 10.3322/caac.21142

Saotome T, Klein L, and Faux S. 2015. Cancer rehabilitation: a barometer for survival? Supportive Care in Cancer 23:3033-3041. DOI 10.1007/s00520-015-2673-1

Sarini J, Fournier C, Lefebvre J-L, Bonafos G, Van JT, and Coche-Dequéant B. 2001. Head and neck squamous cell carcinoma in elderly patients: a long-term retrospective review of 273 cases. Archives of Otolaryngology-Head \& Neck Surgery 127:1089-1092. DOI 10.1001/archotol.127.9.1089

Sattar S, Alibhai SM, Spoelstra SL, Fazelzad R, and Puts MT. 2016. Falls in older adults with cancer: a systematic review of prevalence, injurious falls, and impact on cancer treatment. Supportive Care in Cancer 24:4459-4469.

DOI 10.1007/s00520-016-3342-8

Siddiqui F, and Gwede CK. 2012. Head and neck cancer in the elderly population. Seminars in Radiation Oncology 22:321-333. DOI 10.1016/j.semradonc.2012.05.009

Ungar A, and Rafanelli M. 2015. My older patient with cancer reports falls: What should I do? Journal of Geriatric Oncology 6:419-423.

DOI 10.1016/j.jgo.2015.09.002 
453 Zabrodsky M, Calabrese L, Tosoni A, Ansarin M, Giugliano G, Bruschini R, Tradati N, De Paoli F, 454 Tredici $P$, and Betka J. 2004. Major surgery in elderly head and neck cancer patients: 455 immediate and long-term surgical results and complication rates. Surgical Oncology $456 \quad 13: 249-255$.

457 DOI 10.1016/j.suronc.2004.09.003

458 
Table $\mathbf{1}$ (on next page)

Clinicopathological characteristics of 1712 patients with oral tongue cancer receiving surgery stratified by three age groups 
1 Table 1. Clinicopathological characteristics of 1712 patients with oral tongue cancer

2 receiving surgery stratified by three age groups

\begin{tabular}{|c|c|c|c|c|c|c|c|}
\hline & $\begin{array}{r}\text { Age } \\
n=1476\end{array}$ & $\begin{array}{l}65 \\
86.2 \%) \\
\end{array}$ & $\begin{array}{r}\text { Age 65 } \\
n=178 \\
\end{array}$ & $\begin{array}{l}<75 \\
0.4 \%) \\
\end{array}$ & $\begin{array}{r}\text { Age } \\
\mathrm{n}=\mathbf{5 8} \\
\end{array}$ & $\begin{array}{l}75 \\
.4 \%) \\
\end{array}$ & $p$-value \\
\hline Mean Age (SD) & 48.7( & $.5)$ & 68.7 & & 79.5 & $.9)$ & \\
\hline Median (Range) & $49(21$ & 64) & $69(6$ & 74) & $79(75$ & 92) & \\
\hline Gender & & & & & & & $<0.001$ \\
\hline Male & 1323 & $89.6 \%$ & 145 & $81.5 \%$ & 36 & $62.1 \%$ & \\
\hline Female & 153 & $10.4 \%$ & 33 & $18.5 \%$ & 22 & $37.9 \%$ & \\
\hline Stage & & & & & & & 0.829 \\
\hline $\mathrm{I}$ & 521 & $35.3 \%$ & 67 & $37.6 \%$ & 23 & $39.7 \%$ & \\
\hline II & 346 & $23.4 \%$ & 46 & $25.8 \%$ & 14 & $24.1 \%$ & \\
\hline III & 202 & $13.7 \%$ & 22 & $12.4 \%$ & 9 & $15.5 \%$ & \\
\hline IV & 407 & $27.6 \%$ & 43 & $24.2 \%$ & 12 & $20.7 \%$ & \\
\hline $\mathbf{T}$ classification & & & & & & & 0.151 \\
\hline 1 & 558 & $37.8 \%$ & 74 & $41.6 \%$ & 25 & $43.1 \%$ & \\
\hline 2 & 534 & $36.2 \%$ & 70 & $39.3 \%$ & 25 & $43.1 \%$ & \\
\hline 3 & 138 & $9.3 \%$ & 13 & $7.3 \%$ & 5 & $8.6 \%$ & \\
\hline 4 & 246 & $16.7 \%$ & 21 & $11.8 \%$ & 3 & $5.2 \%$ & \\
\hline $\mathbf{N}$ classification & & & & & & & 0.716 \\
\hline 0 & 1025 & $69.4 \%$ & 134 & $75.3 \%$ & 43 & $74.1 \%$ & \\
\hline 1 & 160 & $10.8 \%$ & 14 & $7.9 \%$ & 6 & $10.3 \%$ & \\
\hline 2 & 288 & $19.5 \%$ & 30 & $16.9 \%$ & 9 & $15.5 \%$ & \\
\hline 3 & 3 & $0.2 \%$ & 0 & $0.0 \%$ & 0 & $0.0 \%$ & \\
\hline Histological grade & & & & & & & 0.847 \\
\hline Well & 444 & $30.1 \%$ & 55 & $30.9 \%$ & 17 & $29.3 \%$ & \\
\hline Moderately & 896 & $60.7 \%$ & 103 & $57.9 \%$ & 34 & $58.6 \%$ & \\
\hline Poorly & 136 & $9.2 \%$ & 20 & $11.2 \%$ & 7 & $12.1 \%$ & \\
\hline Treatment & & & & & & & 0.004 \\
\hline Surgery alone & 868 & $58.8 \%$ & 120 & $67.4 \%$ & 44 & $75.9 \%$ & \\
\hline Surgery + CT or RT & 608 & $41.2 \%$ & 58 & $32.6 \%$ & 14 & $24.1 \%$ & \\
\hline RT alone & 180 & $12.2 \%$ & 23 & $12.9 \%$ & 8 & $13.8 \%$ & \\
\hline CT alone & 58 & $3.9 \%$ & 8 & $4.5 \%$ & 2 & $3.4 \%$ & \\
\hline CCRT & 370 & $25.1 \%$ & 27 & $15.2 \%$ & 4 & $6.9 \%$ & \\
\hline
\end{tabular}


Table 2 (on next page)

Characteristics and treatments of early stage (Stage I-II) and advanced stage (Stage III-IV) patients stratified by three age groups 
Table 2. Characteristics and treatments of early stage (Stage I-II) and advanced stage (Stage III-IV) patients stratified by three age groups

\begin{tabular}{|c|c|c|c|c|c|c|c|c|}
\hline & & Stage I-II & & $\overline{P \text {-value }}$ & & Stage III-IV & & P-value \\
\hline & $<65$ & 65 to $<75$ & $\geq 75$ & & $<65$ & 65 to $<75$ & $\geq 75$ & \\
\hline Numbers & $867(85.3 \%)$ & $113(11.1 \%)$ & $37(3.6 \%)$ & & $609(87.6 \%)$ & $65(9.4 \%)$ & $21(3.0 \%)$ & \\
\hline Mean Age $( \pm$ SD $)$ & $48.6( \pm 8.6)$ & $68.8( \pm 2.6)$ & $80.0( \pm 4.3)$ & & $48.8( \pm 8.3)$ & $68.6( \pm 2.9)$ & $78.6( \pm 2.8)$ & \\
\hline Median (Range) & $49(21-64)$ & $69(65-74)$ & $79(75-92)$ & & $49(27-64)$ & $69(65-74)$ & $79(75-85)$ & \\
\hline Gender & & & & $<0.001$ & & & & $<0.001$ \\
\hline Male & $763(88.0 \%)$ & $92(81.4 \%)$ & $21(56.8 \%)$ & & $560(92.0 \%)$ & $53(81.5 \%)$ & $15(71.4 \%)$ & \\
\hline Female & $104(12.0 \%)$ & $21(18.6 \%)$ & $16(43.2 \%)$ & & $49(8.0 \%)$ & $12(18.5 \%)$ & $6(28.6 \%)$ & \\
\hline Treatment & & & & 0.558 & & & & $<0.001$ \\
\hline Surgery alone & $752(86.7 \%)$ & $96(85.0 \%)$ & $34(91.9 \%)$ & & $116(19.0 \%)$ & $24(36.9 \%)$ & $10(47.6 \%)$ & \\
\hline Surgery + CT or RT & $115(13.3 \%)$ & $17(15.0 \%)$ & $3(8.1 \%)$ & & $493(81.0 \%)$ & $41(63.1 \%)$ & $11(52.4 \%)$ & \\
\hline RT alone & $81(9.3 \%)$ & $9(8.0 \%)$ & $3(8.1 \%)$ & & $99(16.3 \%)$ & $14(21.5 \%)$ & $5(23.8 \%)$ & \\
\hline CT alone & $15(1.7 \%)$ & $3(2.7 \%)$ & $0(0.0 \%)$ & & $43(7.1 \%)$ & $5(7.7 \%)$ & $2(9.5 \%)$ & \\
\hline CCRT & $19(2.2 \%)$ & $5(4.4 \%)$ & $0(0.0 \%)$ & & $351(57.6 \%)$ & $22(33.8 \%)$ & $4(19.0 \%)$ & \\
\hline
\end{tabular}


Table 3(on next page)

Multivariate analyses of risk factors regarding overall survival of all patients ( $n=1712$ ) using Cox Proportional Hazard Model 
1 Table 3. Multivariate analyses of risk factors regarding overall survival of all patients $(\mathrm{n}=$

2 1712) using Cox Proportional Hazard Model

\begin{tabular}{|c|c|c|c|c|}
\hline Covariate & HR & \multicolumn{2}{|c|}{ CI(95\%) } & P-value \\
\hline Male & 1.39 & 1.00 & 1.93 & 0.048 \\
\hline \multicolumn{5}{|l|}{ Age (ref: <65) } \\
\hline $65-<75$ & 1.38 & 1.02 & 1.87 & $\mathbf{0 . 0 3 7}$ \\
\hline$\geqq 75$ & 1.92 & 1.20 & 3.06 & 0.007 \\
\hline \multicolumn{5}{|l|}{ Stage (ref: I+II) } \\
\hline III+IV & 1.64 & 1.07 & 2.50 & 0.022 \\
\hline \multicolumn{5}{|c|}{$\mathrm{T}$ classification (ref: $\mathrm{T}_{1}, \mathrm{~T}_{2}$ ) } \\
\hline $\mathrm{T}_{3}, \mathrm{~T}_{4}$ & 1.42 & 1.10 & 1.84 & 0.008 \\
\hline \multicolumn{5}{|l|}{$\mathrm{N}$ classification (ref: $\mathrm{N}_{0}$ ) } \\
\hline $\mathrm{N}_{1}, \mathrm{~N}_{2}, \mathrm{~N}_{3}$ & 2.41 & 1.70 & 3.42 & $<0.001$ \\
\hline \multicolumn{5}{|c|}{ Histological grade (ref: WD, MD) } \\
\hline $\mathrm{PD}$ & 1.51 & 1.16 & 1.97 & 0.003 \\
\hline \multicolumn{5}{|c|}{ Treatment (ref: Surgery alone) } \\
\hline Surgery +RT alone & 1.07 & 0.77 & 1.48 & 0.683 \\
\hline Surgery $+\mathrm{CT}$ alone & 1.97 & 1.33 & 2.90 & 0.001 \\
\hline Surgery +CCRT & 0.93 & 0.69 & 1.26 & 0.645 \\
\hline
\end{tabular}

3 HR: Hazard ratio; CI: Confidence interval; WD: Well differentiated; MD: Moderately

4 differentiated; PD: Poorly differentiated; RT: Radiotherapy; CT: Chemotherapy; CCRT:

5 Concurrent chemo-radiotherapy. 
Table 4 (on next page)

Multivariate analyses of risk factors regarding overall survival of early-stage (I-II) patients $(n=1017)$ using Cox Proportional Hazard Model 
Table 4. Multivariate analyses of risk factors regarding overall survival of earlystage $(\mathrm{I}-\mathrm{II})$ patients $(\mathrm{n}=1017)$ using Cox Proportional Hazard Model

\begin{tabular}{|c|c|c|c|c|}
\hline Covariate & HR & \multicolumn{2}{|c|}{ CI(95\%) } & P-value \\
\hline \multicolumn{5}{|l|}{ Gender (ref: Female) } \\
\hline Male & 1.64 & 0.92 & 2.94 & 0.095 \\
\hline \multicolumn{5}{|l|}{ Age (ref: <65) } \\
\hline $65-<75$ & 1.43 & 0.87 & 2.34 & 0.158 \\
\hline$\geqq 75$ & 1.22 & 0.49 & 3.03 & 0.664 \\
\hline \multicolumn{5}{|c|}{ Histological grade (ref: WD, MD) } \\
\hline PD & 1.81 & 1.00 & 3.28 & 0.051 \\
\hline \multicolumn{5}{|c|}{ Treatment (ref: Surgery alone) } \\
\hline Surgery +RT alone & 1.95 & 1.19 & 3.22 & 0.009 \\
\hline Surgery $+\mathrm{CT}$ alone & 3.63 & 1.68 & 7.86 & 0.001 \\
\hline Surgery +CCRT & 4.04 & 2.03 & 8.01 & $<\mathbf{0 . 0 0 1}$ \\
\hline
\end{tabular}

HR: Hazard ratio; CI: Confidence interval; WD: Well differentiated; MD: Moderately differentiated; PD: Poorly differentiated; RT: Radiotherapy; CT: Chemotherapy; CCRT: Concurrent chemo-radiotherapy. 
Table 5 (on next page)

Multivariate analyses of risk factors regarding overall survival of advanced stage (III-IV) patients $(n=695)$ using Cox Proportional Hazard Model 
Table 5. Multivariate analyses of risk factors regarding overall survival of advanced stage (III-IV) patients $(n=695)$ using Cox Proportional Hazard Model

\begin{tabular}{|c|c|c|c|c|}
\hline Covariate & HR & \multicolumn{2}{|c|}{ CI(95\%) } & P-value \\
\hline Male & 1.16 & 0.78 & 1.72 & 0.454 \\
\hline \multicolumn{5}{|l|}{ Age $($ ref: $<65)$} \\
\hline $65-<75$ & 1.19 & 0.81 & 1.75 & 0.372 \\
\hline$\geqq 75$ & 2.53 & 1.46 & 4.38 & 0.001 \\
\hline \multicolumn{5}{|c|}{ Histological grade (ref: WD, MD) } \\
\hline $\mathrm{PD}$ & 1.46 & 1.08 & 1.97 & 0.013 \\
\hline \multicolumn{5}{|c|}{ Treatment (ref: Surgery alone) } \\
\hline Surgery +RT alone & 0.65 & 0.44 & 0.95 & 0.028 \\
\hline Surgery $+\mathrm{CT}$ alone & 1.62 & 1.06 & 2.47 & 0.026 \\
\hline Surgery +CCRT & 0.89 & 0.67 & 1.19 & 0.424 \\
\hline
\end{tabular}

HR: Hazard ratio; CI: Confidence interval; WD: Well differentiated; MD: Moderately differentiated; PD: Poorly differentiated; RT: Radiotherapy; CT: Chemotherapy; CCRT:

3 Concurrent chemo-radiotherapy. 
Table 6(on next page)

Causes of mortality of very old patients with stage III-IV tongue cancer 
1 Table 6. Causes of mortality of very old patients with stage III-IV tongue cancer (n=21)

2

\begin{tabular}{|c|c|c|c|c|c|c|}
\hline No & Sex & Age & $\begin{array}{c}\text { Survival } \\
\text { time (days) }\end{array}$ & $\begin{array}{c}\text { Adjuvant } \\
\text { (needed/done) }\end{array}$ & $\begin{array}{c}\text { Cause of } \\
\text { death }\end{array}$ & Details \\
\hline 1 & $\mathrm{~F}$ & 79 & 38 & $\mathrm{Y} / \mathrm{N}$ & Non-cancer & $\begin{array}{l}\text { Sepsis, acute renal failure, } \\
\text { pneumonia, malnutrition, type } \\
\text { II DM (die on post-op day } 10 \text { ) }\end{array}$ \\
\hline 2 & M & 76 & 53 & $\mathrm{Y} / \mathrm{N}$ & Non-cancer & $\begin{array}{l}\text { Pneumonia, respiratory } \\
\text { failure }\end{array}$ \\
\hline 3 & M & 81 & 76 & $\mathrm{Y} / \mathrm{N}$ & Non-cancer & $\begin{array}{l}\text { Severe hyponatremia caused } \\
\text { by syndrome of inappropriate } \\
\text { antidiuretic hormone } \\
\text { secretion (SIADH) }\end{array}$ \\
\hline 4 & $\mathrm{~F}$ & 77 & 102 & $\mathrm{Y} / \mathrm{N}$ & Non-cancer & Pneumonia, DM, HT \\
\hline 5 & M & 85 & 257 & $\mathrm{~N} / \mathrm{N}$ & Non-cancer & $\begin{array}{l}\text { Pneumonia, Poor renal } \\
\text { function, COPD, DM, HT, } \\
\text { anemia, }\end{array}$ \\
\hline 6 & M & 76 & 264 & $\mathrm{Y} / \mathrm{Y}$ & cancer & $\begin{array}{l}\text { Multiple bone metastasis, } \\
\text { poor intake, hospice }\end{array}$ \\
\hline 7 & M & 78 & 294 & $\mathrm{Y} / \mathrm{Y}$ & Unknown & $\begin{array}{l}\text { Medical record of death in } \\
\text { other hospital }\end{array}$ \\
\hline 8 & M & 76 & 323 & $\mathrm{Y} / \mathrm{Y}$ & cancer & $\begin{array}{l}\text { Neck local recurrence and } \\
\text { pneumonia }\end{array}$ \\
\hline 9 & M & 79 & 326 & $\mathrm{Y} / \mathrm{N}$ & cancer & $\begin{array}{l}\text { Cancer recurrence, cachexia, } \\
\text { COPD, DM, major } \\
\text { depression }\end{array}$ \\
\hline 10 & $\mathrm{~F}$ & 79 & 329 & $\mathrm{Y} / \mathrm{Y}$ & cancer & $\begin{array}{l}\text { Lung metastasis, neck } \\
\text { metastasis and trachea } \\
\text { invasion with bleeding }\end{array}$ \\
\hline 11 & M & 81 & 354 & $\mathrm{~N} / \mathrm{N}$ & Non-cancer & $\begin{array}{l}\text { Pneumonia, sepsis, type II } \\
\text { DM, renal failure }\end{array}$ \\
\hline 12 & M & 82 & 365 & $\mathrm{~N} / \mathrm{N}$ & Non-cancer & Atrial fibrillation and flutter \\
\hline 13 & $\mathrm{~F}$ & 79 & 727 & $\mathrm{Y} / \mathrm{Y}$ & Non-cancer & Pneumonia \\
\hline 14 & M & 75 & 992 & $\mathrm{Y} / \mathrm{Y}$ & Non-cancer & $\begin{array}{l}\text { Fall down and femoral } \\
\text { fracture, sepsis, poor } \\
\text { nutrition, hypokalemia }\end{array}$ \\
\hline 15 & $\mathrm{~F}$ & 82 & 486 & $\mathrm{~N} / \mathrm{N}$ & Alive & \\
\hline 16 & M & 75 & 658 & $\mathrm{~N} / \mathrm{N}$ & Alive & \\
\hline 17 & M & 78 & 862 & $\mathrm{Y} / \mathrm{Y}$ & Alive & \\
\hline 18 & M & 76 & 1022 & $\mathrm{Y} / \mathrm{Y}$ & Alive & \\
\hline 19 & $\mathrm{~F}$ & 82 & 1056 & $\mathrm{Y} / \mathrm{Y}$ & Alive & \\
\hline 20 & $\mathrm{M}$ & 76 & 1279 & $\mathrm{Y} / \mathrm{Y}$ & Alive & \\
\hline 21 & $\mathrm{M}$ & 79 & 1442 & $\mathrm{Y} / \mathrm{Y}$ & Alive & \\
\hline
\end{tabular}

3 DM: Diabetes mellitus; HT: Hypertension; COPD: Chronic obstructive pulmonary disease.

4 *Survival time: from day of diagnosis to death or last follow-up dates. 


\section{Figure 1}

Figure 1

Overall survival curves of early-stage (A) and advanced-stage (B) patients.
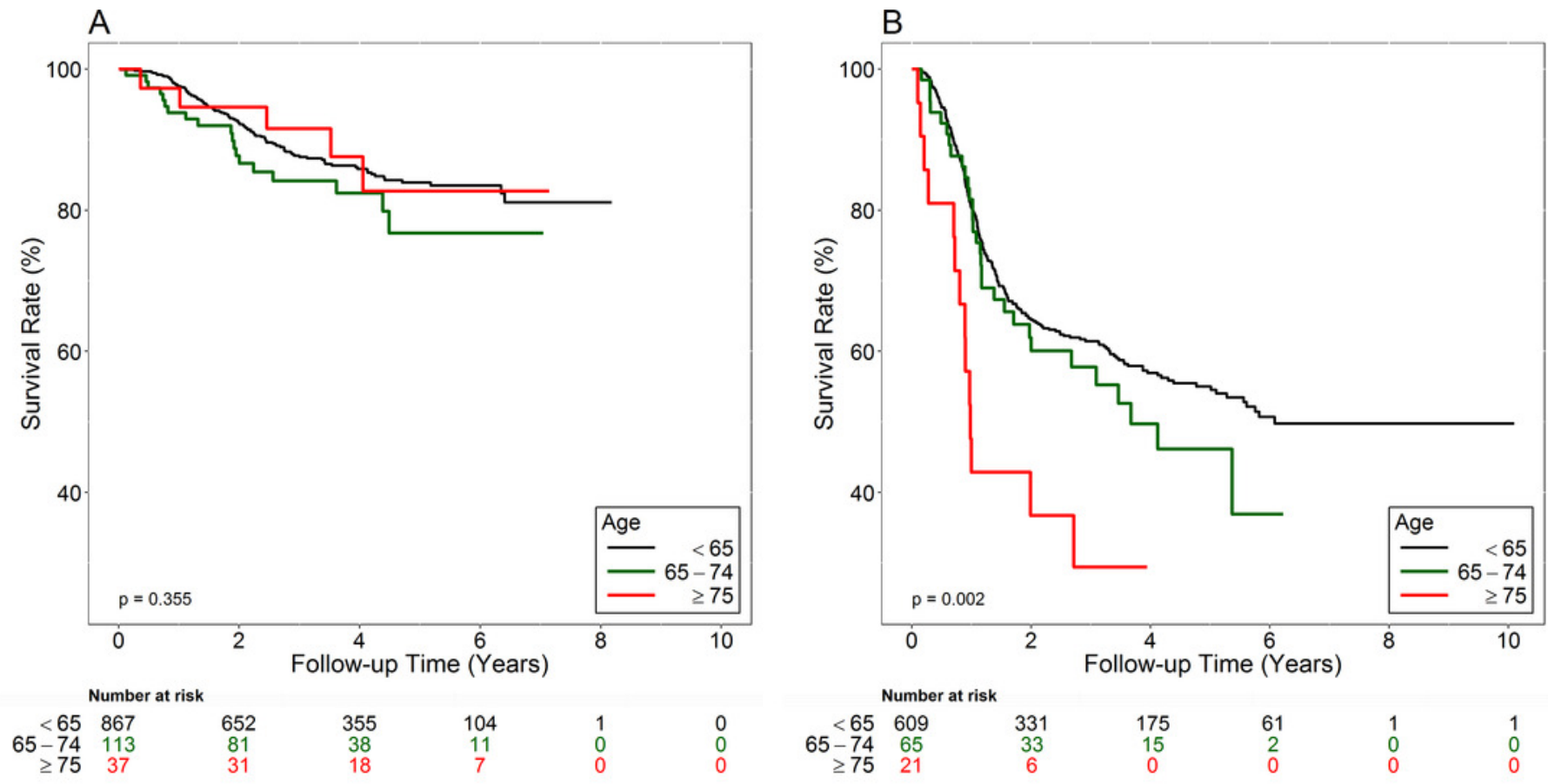